\title{
Strategi Pemasaran Pelayanan Continuous Ambulatory Peritoneal Dialysis di Klinik Khusus Ginjal X Batam Tahun 2016
}

\section{Marketing Strategy of Continuous Ambulatory Peritoneal Dialysis Service at "Klinik Khusus Ginjal X Batam" in 2016}

\author{
Bertha Toha ${ }^{1}$, Vetty Yulianty Permanasari ${ }^{2}$ \\ ${ }^{1}$ Program Studi Kajian Administrasi Rumah Sakit, Fakultas Kesehatan Masyarakat, Universitas Indonesia, Depok, Indonesia \\ ${ }^{2}$ Departemen Administrasi dan Kebijakan Kesehatan, Kesehatan Masyarakat, Universitas Indonesia, Depok, Indonesia
}

Korespondensi: Bertha Toha,

e-mail:bertha_toha@yahoo.com

\begin{abstract}
Abstrak
Saat ini hanya 53\% pasien Gagal Ginjal Terminal (GGT) yang dapat mengakses dialisis dan sebagian besar menjalani HD, padahal biaya untuk melaksanakan CAPD lebih murah dibandingkan HD (P2JK, 2016). Pelayanan CAPD di Klinik Khusus Ginjal X Batam sudah dimulai sejak tahun 2010, namun jumlah pasien CAPD hanya 3\% dari total pasien GGT di klinik tersebut. Tujuan penelitian ini untuk menganalisis Strategi Pemasaran Pelayanan Continuous Ambulatory Peritoneal Dialysis di Klinik Khusus Ginjal X Batam Tahun 2016. Desain penelitian yang digunakan adalah analitik deskriptif dengan pendekatan kuantitatif dan kualitatif. Instrument dan Tahapan analisis yang digunakan adalah strategi Fred R. David yang kemudian dilanjutkan dengan Segmenting, Targeting dan Positioning, Ialu menentukan bauran pemasaran (Product, Promotion, Price, Place, People, Physical evidence, Process, Customer Service). Klinik telah menetapkan tarif pelayanan yang disesuaikan dengan tarif paket INA-CBG's, namun belum melakukan perhitungan biaya satuan. Strategi Pemasaran yang layak dan sesuai dengan analisis situasi adalah: Market Penetration dan Product Development. Pemasaran produk pelayanan di Klinik Khusus Ginjal X Batam dapat berupa periklanan melalui berbagai media seperti talk show di radio, talk show di stasiun televisi di kota Batam, dan leaflet; penyebaran leaflet di ruangan pelayanan IImu Penyakit Dalam; promosi penjualan, dan pembinaan dokter puskesmas. Selain itu bisa dilakukan promosi secara online. Untuk menghindari terjadinya asimetric information, maka dokter penanggungjawab memberikan edukasi yang komprehensif terhadap terapi CAPD.
\end{abstract}

Kata kunci : Terapi pengganti ginjal, Transplantasi ginjal, Hemodialisis, CAPD, Strategi Pemasaran, Bauran Pemasaran, Analisis situasi

\begin{abstract}
Currently only 53\% of patients with end-stage renal disease that can access dialysis and mostly get Hemodialysis (HD), whereas the cost to Continous Ambulatory Peritoneal Dialysis (CAPD) cheaper than HD (Ministry of Health, 2016). Services of CAPD in Clinic for Kidney Disease X. Batam began since 2010, but the number of CAPD patients only 3\% of the end stage renal disease patients there. The purpose of this study to analyze the Marketing Strategy of Continuous Ambulatory Peritoneal Dialysis Services at the Clinic for Kidney Disease X Batam Year 2016. The design of the study is an analytic descriptive with quantitative and qualitative approaches. Stages of analysis used Fred R. David strategies and followed by Segmenting, Targeting and Positioning, and then determine the marketing mix (Product, Promotion, Price, Place, People, Physical Evidence, Process, Customer Service). The Clinic has set tariffs adjusted rates INA-CBG's package but has not calculated the cost of the unit. A Marketing strategy that good and proper with the analysis of the situation are: Market Penetration and Product Development. Product marketing services in Clinic for Kidney Disease X Batam can be advertised through various media such as radio talk shows, Local Batam station of television talk shows and leaflets; distribute leaflets in the service room of Medicine; sales promotion, and training for doctors in health primary care. In addition, promotion of CAPD can use online or social media. In order to avoid asimetric information, the doctors have responsible for giving a comprehensive education on CAPD therapy.

Keywords: renal replacement therapy, kidney transplantation, hemodialysis, CAPD, Marketing Strategy, Marketing Mix, Analysis of the situation
\end{abstract}

\section{Pendahuluan}

Gagal ginjal kronik menjadi masalah besar dunia karena sulit disembuhkan. Di dunia prevalensi gagal ginjal kronis menurut ESRD Patients (End-Stage Renal Disease) pada tahun 2013 sebanyak 1.000 sampai 1.300 per juta populasi dan yang diobati hanya 600 dan 1000 pasien per penduduk juta (USRDS, 2013). Di Indonesia angka kejadian gagal ginjal kronis berdasarkan data dari Riskesdas pada tahun 2013, prevalensi gagal ginjal kronis 0,2\% dari penduduk Indonesia. Hanya $60 \%$ dari pasien gagal ginjal kronis tersebut yang menjalani terapi dialisis (Riskesdas, 2013).

Terdapat tiga modalitas pengganti terapi ginjal, yakni hemodialisa (HD) dan Continous Ambulatory Peritoneal Dialysis (CAPD), serta transplantasi ginjal 
yang dijadikan pilihan treatment pada pasien dengan GGK Tiga modalitas terapi ini termasuk dalam paket manfaat dalam Jaminan Kesehatan Nasional (JKN). Menurut P2JK (2016), diperkirakan hanya $53 \%$ pasien saat ini yang dapat mengakses dialisis dan sebagian besar menjalani HD, padahal biaya untuk melaksanakan PD lebih murah dibandingkan HD. Dialisis telah menyerap pembiayaan lebih dari 1,5 triliun rupiah pada tahun 2014 , menduduki peringkat kedua dalam hal biaya dikeluarkan oleh Badan Penyelenggara Jaminan Sosial (BPJS) Kesehatan.

Pelayanan CAPD di Klinik Khusus Ginjal X Batam sudah dimulai sejak tahun 2010. Saat ini Sehingga djumlah pasien CAPD di klinik tersebut hanya 5 orang pasien dari 169 pasien GGT. mas. Strategi pemasaran yang telah dilakukan saat ini belum berhasil meningkatkan jumlah pasien CAPD karena belum diketahuinya pasar sasaran yang dilayani. Oleh karena itu diperlukan analisis segmenting, targeting dan positioning pasar pelayanan CAPD. Selain itu perlu juga dilakukan analisis bauran pemasaran yang mencerminkan unsur-unsur tradisional bauran pemasaran seperti produk, price, promotion, place, people, process, customer service dan physical evidence.

\section{Metode Penelitian}

Desain penelitian yang digunakan adalah analitik deskriptif dengan menggunakan pendekatan kuantitatif dan kualitatif. Pemilihan desain penelitian deskriptif untuk melihat gambaran atau deskripsi secara jelas dan rinci tentang bauran pemasaran di klinik Khusus Ginjal X Batam Tahun 2016.

Pendekatan kualitatif digunakan untuk mendapatkan informasi dengan melakukan wawancara, observasi, telaah dokumen, dan diskusi dengan cara Consensus Desicion Making Group (CDMG), sedangkan kuantitatif dilakukan dengan menyebarkan kuesioner kepada pasien hemodialisis di Klinik Khusus Ginjal X Batam untuk mengetahui segmentasi berdasarkan geografi (wilayah tempat tinggal), demografi (usia, jenis kelamin, jenis pekerjaan, tingkat pendidikan, tingkat pendapatan), psikografi (sumber informasi, alasan memilih dan penanggung biaya di Klinik Khusus Ginjal X Batam) dan perilaku (lama HD, pengetahuan keberadaan CAPD, sumber informasi CAPD).

Instrumen yang digunakan dalam penelitian ini berupa lembaran kuesioner, cek list indikasi dan kontraindikasi CAPD, lembar pertanyaan untuk informan CAPD, lembar pedoman analisis situasi.
Tahapan analisis yang digunakan adalah strategi Fred R.David yang kemudian dilanjutkan dengan Segmenting, Targeting dan Positioning, serta menentukan bauran pemasaran (Product, Promotion, Price, Place, People, Physical evidence, Process, Customer Service).

Metode Pengumpulan Data yaitu Menganalisis data primer yang diperoleh secara kuantitatif dan kualitatif. Data untuk analisis kuantitatif didapatkan dengan menyebarkan lembaran kuesioner dan lembaran cek list kepada pasien hemodialisis Klinik Khusus Ginjal X Batam. Data tersebut digunakan untuk mengetahui besaran frekuensi pada masing-masing variabel sebagai dasar penentuan segmenting dan targeting. Data primer kualitatif diperoleh melalui wawancara mendalam dengan pemilik, dokter pelaksana harian dan perawat mahir CAPD. Selain itu dilakukan konsensus dengan orang-orang yang mempunyai wewenang untuk mengambil keputusan atau CDMG yaitu : Ketua Yayasan Pembinaan Asuhan Bunda, Penanggung jawab Klinik Khusus Ginjal X Batam, Dokter Pelaksana Harian, Kepala Perawat, Kepala Teknisi, Kepala Administrasi dan Kepala Keuangan.

Data Sekunder diperoleh dari hasil telaah dan penelusuran dokumen seperti data rekam medik, Profil Klinik Khusus Ginjal X Batam dan laporan Indonesian Renal Registry (IRR) Klinik Khusus Ginjal X Batam.

Analisis data kualitatif dilakukan dengan cara berikut :

1. Mengumpulkan semua informasi yang didapat dari hasil wawancara, observasi, telaah dokumen, dan diskusi dengan orang-orang dalam grup CDMG

2. Data yang mempunyai karakteristik yang sama menurut pola jawabannya diinterpretasikan dalam bentuk uraian untuk mendukung data kuantitatif.

\section{Hasil Penelitian}

Dari hasil wawancara dapat dinilai bahwa pelayanan CAPD di Klinik Khusus Ginjal X Batam sudah dimulai sejak tahun 2010 dan hanya ada satu jenis pelayanan CAPD yaitu pergantian transfer set yang dilakukan terhadap 1 orang pasien travelling. Sejak tahun 2010 s/d 2016 hanya ada 10 pasien yang dilayani, dan 4 orang pasien sudah meninggal sehingga tersisa hanya 5 pasien yang dilayani saat ini. Padahal CAPD sudah ada di Indonesia sejak tahun 1985. Sedikitnya jumlah pasien pelayanan CAPD 
menggambarkan sosialisasi mengenai adanya TPG berupa CAPD masih belum optimal. Banyak masyarakat yang belum mengenal CAPD, sama halnya di Klinik Khusus Ginjal X Batam.

Pada tahun 2012 pernah dilakukan workshop operasi pemasangan catheter tenckhoff yang diadakan di Rumah Sakit Budi Kemuliaan Batam dan diikuti oleh dokter-dokter spesialis bedah di Kepulauan Riau. Ada 2 pasien CAPD pada tahun 2012 tersebut. Namun berdasarkan data IRR Klinik Khusus Ginjal X Batam sampai tahun 2013 tidak ada penambahan pasien CAPD baru. Tahun 2014 ada 3 pasien CAPD baru, 1 orang pasien CAPD baru di Tahun 2015 dan 3 pasien CAPD baru di Tahun 2016.

Berdasarkan data IRR di diketahui bahwa sejak tahun 2012 s/d 2016 hanya ada 1 orang pasien yang operasi pemasangan catheter tenckhoff nya dilakukan di Rumah Sakit Budi Kemuliaan Batam, yaitu pada saat workshop dilakukan dan yang melakukan operasi adalah dokter yang mengajarkan operasi tersebut.

Pasien-pasien lain melakukan operasi pemasangan catheter tenckhoff di Jakarta, Bandung, Malaysia dan Singapura. Pasien-pasien CAPD tersebut tidak melakukan operasi di Rumah Sakit Budi Kemuliaan Batam akibat kurangnya informasi bahwa operasi tersebut sudah dapat dilakukan di rumah sakit tersebut. Alasan lainnya karena dokter spesialis bedah yang mengikuti workshop merasa belum layak dan percaya diri untuk melakukan operasi pemasangan catheter tenckhoff.
Dari hasil wawancara seperti diuraikan di atas, pelayanan CAPD yang belum ada di Klinik Khusus Ginjal X Batam adalah: Implant/Insersi/Pemasangan Catheter Tenckhoff. Hal ini disebabkan belum adanya tenaga nephrolog/internis/spesialis bedah/dokter umum yang dapat melakukan pemasangan catheter tenckhoff dan dokter yang pernah ikut workshop sudah pindah tempat.

Analisis situasi dari Klinik Khusus Ginjal X Batam memiliki kekuatan dalam segi i) kualitas SDM yang baik, ii)jumlah mesin HD terbanyak di Kepulauan Riau, iii)cairan dialisat dapat diproduksi sendiri, iv)mempunyai dokter dan perawat mahir CAPD sedangkan untuk kelemahan interal yaitu i)bagian marketing yang kurang aktif, ii) kurangnya sosialisasi, dan iii)sistem informasi manajemen yang belum baik. Peluang yang dapat dimanfaatkan meliputi i) adanya kebijakan pasar bebas JKN, ii)pelayanan CAPD ditanggung biayanya oleh BPJS Kesehatan, iii)terletak di pusat kota Batam, iv)adanya operasi metode Bandung, v)adanya kompetitor. Tantangan eksternal yang menjadi hambatan meliputi i) masih sedikit orang yang mengenal CAPD pada kelompok penderita GGT dan ii)kurangnya dukungan dari Pemerintah. Dari komponen SWOT tersebut dapat dirumuskan strategi, dan dari hasil uji matriks internal dan eksternal, matriks TOWS dan matriks SPACE maka alternatif strategi yang dianjurkan dapat dilihat pada Tabel 1 .

Dilihat dari Tabel 1, maka alternatif strategi terbaik adalah :

Tabel 1. Tabel Penentuan Strategi Terpilih Tahap Matching Stage

\begin{tabular}{llcc}
\hline \multicolumn{1}{c}{ Alternatif Strategi } & Matriks IE & Matriks SPACE & Matriks TOWS \\
& & & \\
\hline 1. Market Penetration & + & + & + \\
2. Market Development & - & + & + \\
3. Product Development & + & + & + \\
4. Backward Integration & - & + & - \\
5. Forward Integration & - & + & - \\
6. Horizontal Integration & - & + & - \\
7. Conglomerate Diversification & - & + & + \\
8. Concentric Diversification & - & + & + \\
9. Horizontal Diversification & - & - & - \\
10. Related Divers & - & - & \\
11. Vertical Integration & - & & \\
\hline
\end{tabular}




\section{1) Market Penetration}

Strategi untuk meningkatkan pangsa pasar untuk produk atau jasa yang ada sekarang melalui usaha-usaha pemasaran yang lebih intensif. Strategi ini dipilih bila pasar belum jenuh, penggunaan dari pelanggan meningkat, pangsa pasar dari pesaing menurun sedangkan total dari industri meningkat atau korelasi antar keuntungan dan biaya pemasaran tinggi.

\section{2) Product Development}

Strategi yang berusaha meningkatkan penjualan dengan jalan memperbaiki atau memodifikasi produk atau jasa yang ada. Strategi ini dipilih bila organisasi mempunyai produk sukses yang sudah matang dengan menarik pelanggan yang puas terhadap produk baru, adanya persaingan industri dengan ciri teknologi yang cepat berkembang, pesaing utama menawarkan produk dengan kualitas yang lebih baik dengan harga bersaing, organisasi bersaing dalam industri dengan pertumbuhan tinggi, atau mempunyai kemampuan riset atau pengembangan yang kuat.

Tabel 2. Segmentasi Demografis Pasien Hemodialisis di Klinik Khusus Ginjal X Batam

November 2016

\begin{tabular}{|c|c|c|}
\hline & $\begin{array}{l}\text { Frekuensi } \\
\text { (n) }\end{array}$ & $\begin{array}{l}\text { Persentase } \\
(\%)\end{array}$ \\
\hline \multicolumn{3}{|l|}{ Usia } \\
\hline $0-17$ tahun (anak-anak dibawah umur) & 0 & $0 \%$ \\
\hline 18 - 65 tahun (pemuda) & 127 & $91,4 \%$ \\
\hline 66 - 79 tahun (setengah baya) & 12 & $8,6 \%$ \\
\hline $80-99$ tahun (orang tua) & 0 & $0 \%$ \\
\hline$>100$ tahun (orang tua berusia panjang) & 0 & $0 \%$ \\
\hline Total & 139 & $100 \%$ \\
\hline \multicolumn{3}{|l|}{ Jenis Kelamin } \\
\hline Laki-laki & 82 & $59 \%$ \\
\hline Perempuan & 57 & $41 \%$ \\
\hline Total & 139 & $100 \%$ \\
\hline \multicolumn{3}{|l|}{ Jenis Pekerjaanw } \\
\hline Tidak bekerja & 34 & $24,5 \%$ \\
\hline PNS / BUMN & 8 & $5,8 \%$ \\
\hline Pegawai Swasta & 14 & $10,1 \%$ \\
\hline Wiraswasta & 28 & $20,1 \%$ \\
\hline Ibu Rumah Tangga & 51 & $36,7 \%$ \\
\hline Pensiunan & 2 & $1,4 \%$ \\
\hline Pelajar / Mahasiswa & 1 & $0,7 \%$ \\
\hline Lain-lain & 1 & $0,7 \%$ \\
\hline Total & 139 & $100 \%$ \\
\hline \multicolumn{3}{|l|}{ Tingkat Pendidikan } \\
\hline Tidak sekolah & 14 & $10,1 \%$ \\
\hline SD & 25 & $18,0 \%$ \\
\hline SMP & 28 & $20,1 \%$ \\
\hline SMA dan sederajat & 48 & $34,5 \%$ \\
\hline Perguruan Tinggi & 20 & $14,4 \%$ \\
\hline Lain-lain & 4 & $2,9 \%$ \\
\hline Total & 139 & $100 \%$ \\
\hline \multicolumn{3}{|l|}{ Tingkat Pendapatan } \\
\hline$<2$ juta & 6 & $4,3 \%$ \\
\hline $2-5$ juta & 29 & $20,9 \%$ \\
\hline$>5$ juta & 16 & $11,5 \%$ \\
\hline Tidak berpendapatan & 88 & $63,3 \%$ \\
\hline Total & 139 & \\
\hline
\end{tabular}

Pasien yang hemodialisis sebagian besar dari golongan usia produktif sebesar $91,4 \%$, berjenis ke- lamin laki-laki (59\%) dan tingkat pendidikan SMA atau sederajat $(34,5 \%)$. Dari tingkat pendapatan kebanyakan pasien tidak berpendapatan (63,3\%).

Tabel 3. Segmentasi Psikografis Pasien Hemodialisis

di Klinik Khusus Ginjal X Batam November 2016

\begin{tabular}{lcc}
\hline & $\begin{array}{c}\text { Frekuensi } \\
\text { (n) }\end{array}$ & $\begin{array}{c}\text { Persentase } \\
(\mathbf{\%})\end{array}$ \\
\hline Sumber Informasi mengenai Klinik & & \\
Khusus Ginjal X Batam & & \\
$\quad$ Dokter rujukan / puskesmas & 107 & $77 \%$ \\
Keluarga / kerabat & 29 & $20,9 \%$ \\
Browsing internet & 1 & $0,7 \%$ \\
Brosur / spanduk & 0 & $0 \%$ \\
Lain-lain & 2 & $1,4 \%$ \\
Total & 139 & $100 \%$ \\
Alasan Pasien Memilih Hemodialisis & & \\
di Klinik Khusus Ginjal X Batam & & \\
Dekat rumah & 11 & $7,9 \%$ \\
Rujukan RS / puskesmas & 40 & $28,8 \%$ \\
Pelayanan yang bagus & 77 & $55,4 \%$ \\
Dokter yang ahli & 9 & $6,5 \%$ \\
Lain-lain & 2 & $1,4 \%$ \\
Total & 139 & $100 \%$ \\
Penanggung biaya hemodialisis & 139 & $100 \%$ \\
BPJS & 0 & $0 \%$ \\
Non BPJS & 139 & \\
Total & & \\
\hline
\end{tabular}

Dalam Tabel. 3 menunjukan segmentasi psikografis dimana sebesar 77\% sumber informasi mengenai Klinik Khusus Ginjal X Batam didapatkan dari dokter rujukan atau puskesmas, kebanyakan memilih hemodialisis di Klinik Khusus Ginjal X karena pelayanan yang bagus dan 100\% penanggung biaya adalah BPJS Kesehatan.

Dalam Tabel. 4 menunjukan sebesar 64\% pasien menghabiskan waktu selama 0-2 tahun untuk Hemodialisis. Sebagian (48,9\%) pasien belum mengetahui informasi mengenai pelayanan CAPD dan sumber informasi mengenai adanya pelayanan CAPD sebagian besar didapatkan dari Dokter/petugas RS (49,3\%).

\section{Pembahasan \\ Segmenting}

Secara segmenting geografi pasien yang tinggal di luar pulau Batam dapat dijadikan target sasaran untuk pemasaran produk pelayanan CAPD. Karena dengan CAPD pasien diluar pulau Batam dapat meminimalisasi dan mengefisiensikan waktu dan biaya transportasi. Segmentasi demografis berdasarkan hasil tabel dapat dianalisis bahwa golongan usia pemuda laki-laki dapat dijadikan target pemasaran 
pelayanan CAPD. Pasien dengan tingkat pendidikan SMA dan sederajat serta Perguruan Tinggi dapat menjadi target pemasaran dengan cara sosialisasi melalui pemberian leaflet CAPD, seminar untuk awam dan penyuluhan.

Tabel 4. Segmentasi Demografis Pasien Hemodialisis di Klinik Khusus Ginjal X Batam November 2016

\begin{tabular}{lcc}
\hline & $\begin{array}{c}\text { Frekuensi } \\
(\mathbf{n})\end{array}$ & $\begin{array}{c}\text { Persentase } \\
(\%)\end{array}$ \\
\hline Lama Hemodialisis di Klinik Khusus & & \\
Ginjal X Batam & 0 & $0 \%$ \\
$>15$ tahun & 0 & $0 \%$ \\
$12-14$ tahun & 4 & $2,9 \%$ \\
$9-11$ tahun & 15 & $10,8 \%$ \\
$6-8$ tahun & 31 & $22,3 \%$ \\
$3-5$ tahun & 89 & $64 \%$ \\
$0-2$ tahun & 139 & $100 \%$ \\
Total & & \\
Pengetahuan Pasien Mengenai & & \\
Keberadaan Pelayanan CAPD & 71 & $51,1 \%$ \\
Tahu & 68 & $48,9 \%$ \\
Tidak Tahu & 139 & $100 \%$ \\
Total & & \\
Sumber Informasi Mengenai & & \\
Keberadaan Pelayanan CAPD & 3 & $4,2 \%$ \\
Keluarga & 35 & $49,3 \%$ \\
Dokter / Petugas RS & 1 & $1,4 \%$ \\
Dokter Rujukan / Puskesmas & $6,5 \%$ \\
Internet & 6 & $2,8 \%$ \\
Brosur / Spanduk & 2 & $33,8 \%$ \\
Lain-lain & 24 & $100 \%$ \\
Total & 71 & \\
\hline
\end{tabular}

Segmentasi Psikografis dapat menyasar dokter perujuk/Puskesmas dan dokter perujuk dari RS untuk dapat dilakukan pembinaan dan membantu promosi dan informan pelayanan CAPD dengan diadakannya seminar dan penyebaran leaflet berisikan informasi apa itu CAPD dan bagaimana menjadi pasien CAPD. Dilihat dari segmentasi perilaku, dokter dan petugas RS juga memiliki peranan penting dalam peningkatan informasi mengenai CAPD.

\section{Targeting}

Target pasar sasaran guna pengembangan CAPD di Klinik Khusus Ginjal X Batam adalah pasien yang membutuhkan terapi pengganti ginjal berupa: Transplantasi, Hemodialisis atau CAPD dengan kualitas pelayanan yang baik, sedangkan yang dapat dijadikan sebagai target pemasaran pelayanan CAPD adalah:

1. Pasien Gagal Ginjal Terminal baru yang memerlukan Terapi Pengganti Ginjal .

2. Pasien Gagal Ginjal Terminal lama yang sudah menjalani Hemodialisis dan memenuhi syarat untuk dapat beralih ke CAPD.

3. Pasien hemodialisis yang tinggal di Pulau Bintan dan Karimun.

4. Pasien gagal ginjal yang tinggal di Kecamatan Bulang dan Galang.
5. Pasien gagal ginjal berusia golongan pemuda.

6. Pasien berjenis kelamin laki-laki.

7. Pasien dengan jenis pekerjaan ibu rumah tangga.

8. Pasien dengan tingkat pendidikan SMA sederajat dan Perguruan Tinggi.

Tabel 5. Crosstabulation Pengetahuan Tentang Keberadaan Pelayanan CAPD di Klinik Khusus Ginjal X Batam dan kebersediaan pasien hemodialisis beralih pelayanan CAPD.

\begin{tabular}{llccc}
\hline & & \multicolumn{2}{c}{ Bersedia } & \\
\cline { 3 - 4 } & & Bersedia & $\begin{array}{r}\text { Tidak } \\
\text { Bersedia }\end{array}$ & \\
\hline $\begin{array}{l}\text { Pengetahuan } \\
\begin{array}{l}\text { Keberadaan } \\
\text { Pelayanan CAPD } \\
\text { di Klinik Khusus }\end{array}\end{array}$ & Tahu & 13 & 58 & 71 \\
$\begin{array}{l}\text { Ginjal X Batam. } \\
\text { Tidak }\end{array}$ & Tahu & 7 & 61 & 68 \\
Total & & 20 & 119 & 139 \\
\hline
\end{tabular}

\section{Place}

Lokasi Klinik Khusus Ginjal X Batam terletak strategis di tengah kota Batam dan mudah dijangkau, baik dengan kendaraan umum maupun pribadi, sehingga memudahkan konsumen untuk datang dan mendapatkan pelayanan di Klinik Khusus Ginjal X Batam.

\section{Promotion}

Kegiatan promosi yang dilakukan oleh Klinik Khusus Ginjal X Batam dalam mempromosikan pelayananan CAPD adalah sebagai berikut :

1. Pembinaan terhadap tenaga kesehatan di Puskesmas/Pusat Pelayanan Kesehatan Tingkat Satu/ Rumah Sakit berupa penyebaran leaflet dan seminar. Selain tenaga kesehatan di Puskesmas/Pusat Pelayanan Kesehatan Tingkat Satu/Rumah Sakit, anak sekolah usia SMP dan SMA dapat juga menjadi target untuk dilakukan pembinaan,

2. Periklanan melalui berbagai media seperti talk show di radio, talk show di stasiun televisi di kota Batam, dan leaflet.

3. Promosi penjualan, salah satunya dengan cara berpromosi online melalui website dan media sosial atau yang sering disebut dengan Social Media Marketing. Misalnya melalui facebook, instagram, whatsapp group, dll, majalah kesehatan online lokal, you-tube dan mengirimkan email mengenai informasi mengenai pelayanan CAPD. Selain dengan gambar desain promosi bisa dengan cara 
menampilkan video mengenai pelayanan CAPD, apa itu CAPD, bagaimana menggunakan pelayanan CAPD dan benefit dari CAPD.

4. Mencetak dan memberikan secara gratis kalender berisikan informasi pelayanan yang ada di Klinik Khusus Ginjal X, salah satunya pelayanan CAPD.

\section{People}

Orang-orang yang terlibat baik langsung maupun tidak langsung dengan pelayanan CAPD adalah: CS (cleaning service) yang menjaga; orang bagian pendaftaran yang memberikan pelayanan secara ramah dan tepat; dokter dan perawat mahir CAPD; Supir antar jemput dokter pemberi pelayanan CAPD dan home visit; perawat mahir CAPD; ahli gizi yang menilai gizi pasien CAPD, petugas laboratorium; apoteker dan asisten apoteker yang membantu dalam hal pengadaan alkes dan obat pasien CAPD; maintenance yang menjaga, menjamin dan memperbaiki agar pasien dapat merasakan kenyamanan ruangan yang ada; petugas PMI (Palang Merah Indonesia) yang siap membantu dalam hal pengadaan darah untuk transfusi darah; petugas rekam medis yang membantu dalam hal rekam medis; kasir atau bagian keuangan yang mengurus mengenai urusan keuangan; dan teknisi yang membantu merawat dan memperbaiki peralatan medis dan non medis. Selain ramah, terampil, mahir, memberikan kenyamanan pasien CAPD juga akan dilayani oleh orang yang sopan dan selalu memberikan informasi yang tepat dan benar.

\section{Physical Evidance}

Konsumen jasa dapat mengandalkan tanda-tanda dari bukti fisik untuk mengetahui kualitas pelayanan CAPD terutama bagi konsumen yang tidak mengetahui sama sekali tentang pelayanan CAPD tersebut. Pasien calon penerima pelayanan CAPD dapat mengetahui lebih jelas mengenai CAPD dengan diadakannya seminar/penyuluhan/testimoni pasien CAPD. Berdasarkan telaah dokumen dapat disimpulkan bahwa pasien CAPD lebih produktif, dapat beraktivitas lebih baik dan dengan kesehatan lebih baik dibandingkan saat menjalani HD.

\section{Process}

Pasien yang datang ke Klinik Khusus Ginjal X Batam akan melewati proses sebagai berikut: Pendaftaran $\rightarrow$ Menunggu giliran untuk ketemu dengan dokter mahir CAPD $\rightarrow$ Konsultasi dengan dokter mahir CAPD $\rightarrow$ Operasi pemasangan catheter tenckhoff oleh dr Spesialis Bedah $\rightarrow$ Perawatan luka post operasi dan exit site $\rightarrow$ Pelatihan perawatan luka post operasi dan exit site $\rightarrow$ Pelatihan pertukaran cairan peritoneal dialisis $\rightarrow$ Edukasi gizi $\rightarrow$ Peresepan obat dan alkes $\rightarrow$ Pengambilan obat dan alkes $\rightarrow$ Pulang.

Proses pada pasien hemodialisis lebih praktis hanya terdiri dari: Pendaftaran $\rightarrow$ Hemodialisis $\rightarrow$ Pemeriksaan Laboratorium dan atau Transfusi Darah $\rightarrow$ Pulang.

\section{Customer Service}

Pemberi layanan pelanggan yang terlibat dalam pemberian pra pelayanan CAPD adalah petugas pendaftaran/administrasi dan keuangan. Pemberi pelayanan pada saat tindakan adalah dokter dan perawat ahli CAPD, selanjutnya pemberi layanan pasca tindakan adalah orang di bagian farmasi, laboratorium, PMI dan kasir.

\section{Kesimpulan dan Saran \\ Kesimpulan}

1. Strategi Pemasaran Pelayanan CAPD di Klinik Khusus Ginjal X yang sesuai dengan analisis situasi adalah:

1) Market Penetration

2) Product Development

2. Segmentasi untuk pelayanan CAPD adalah:

1) Segmentasi geografis: pasien yang tinggal di Pulau Bintan dan Karimun, tinggal di Kecamatan Galang dan Bulang.

2) Segmentasi demografis: usia pemuda, laki-laki, ibu rumah tangga, pendidikan SMA sederajat dan Perguruan Tinggi, Pendapatan

3) Segmentasi Psikografis: pasien BPJS, dokter puskesmas / rumah sakit.

4) Segmentasi Perilaku: sebagian belum tahu tentang CAPD dan keberadaan pelayanan CAPD di Klinik Khusus Ginjal X Batam.

3. Targeting untuk pelayanan CAPD ini adalah:

1) Pasien Gagal Ginjal Terminal Baru yang memerlukan Terapi Pengganti Ginjal .

2) Pasien Gagal Ginjal Terminal lama yang sudah menjalani Hemodialisis dan memenuhi syarat untuk dapat beralih ke CAPD.

4. Positioning untuk pelayanan CAPD adalah:

1) Klinik Khusus Ginjal $X$ Batam merupakan satu-satunya pemberi pelayanan CAPD di kota Batam.

5. Bauran pemasaran

1) Product yang dikembangkan: pelayanan CAPD 
2) Price, Tarif yang digunakan mengacu pada tarif INA CBG's. Klinik belum melakukan perhitungan biaya satuan pelayanan CAPD.

3) Place, Lokasi strategis dan mudah dijangkau, sehingga memudahkan konsumen untuk datang, baik dengan kendaraan umum maupun pribadi.

4) Promotion, Kegiatan promosi yang dilakukan adalah sebagai berikut :

a) Pembinaan terhadap tenaga kesehatan di puskesmas/Pusat Pelayanan Kesehatan Tingkat Satu/Rumah Sakit (leaflet/seminar).

b) Periklanan melalui berbagai media seperti talk show di radio, talk show di stasiun televisi di kota Batam, dan leaflet.

c) Promosi penjualan. Salah satunya bisa dengan cara berpromosi online melalui website.

5) People, Orang-orang yang memberikan Pelayanan CAPD selain ramah, terampil, mahir, memberikan kenyamanan pasien CAPD sopan dan selalu memberikan informasi yang tepat dan benar.

6) Physical Evidence, Pasien CAPD lebih produktif, dapat beraktivitas lebih baik dibanding pasien HD dan kesehatan lebih baik dibandingkan saat menjalani HD.

7) Process, Lebih praktis proses pasien hemodialisis

8) Customer Service, Pemberi layanan pelanggan yang terlibat dalam pemberian pelayanan CAPD pra pelayanan, pelayanan dan pasca pelayanan.

\section{Saran}

Dalam pengembangan pelayanan CAPD di Klinik Khusus Ginjal X Batam disarankan agar dalam melakukan pemasaran produk pelayanan dapat berupa periklanan melalui berbagai media seperti talk show di radio, talk show di stasiun televisi di kota Batam, dan leaflet yang disebarkan di ruangan pelayanan Ilmu Penyakit Dalam atau diruangan publik lainnya di rumah sakit; promosi penjualan, dan pembinaan dokter puskesmas. Selain itu bisa dilakukan promosi secara online dan offline. Selanjutnya dokter di Klinik Khusus Ginjal X Batam dan di Rumah Sakit Budi Kemuliaan Batam dapat diberangkatkan ke Bandung untuk mengikuti pelatihan operasi pemasangan catheter tenckhoff metode Bandung untuk meningkatkan skill dokter dalam pelayanan CAPD.Salah satu strategi dalam kendali biaya dan mutu adalah melakukan perhitungan biaya satuan pelayanan CAPD.

\section{Daftar Pustaka}

Ayuningtyas, 2013, Perencanaan Strategis Untuk Organisasi Pelayanan Kesehatan, Edisi Kedua, Jakarta : PT. Raja Grafindo Persada

Biro Komunikasi dan Pelayanan Masyarakat Kementerian Kesehatan RI, 2016, RSUP Sanglah Siap Layani Cangkok Ginjal, Denpasar : http:// www.depkes.go.id/article/print/16013000003/ rsup-sanglah-siap-layani-cangkok-ginjal.html, , Diunduh 28 JANUARI 2016, 00:00:00

Greg Proctor, 2009, Handout Patient, Denver Neflology

IRR, 2016, Home Page Indonesian Renal Registry, http://www.indonesianrenalregistry.org, diunduh 10 Maret 2016.

Kolf, W.J., 1943, Journal of The American Society of Nephrology, The Artificial Kidney: a dialyser with a great area, Reprinted from Acta. Med. Scand. CXVII:121-b34, 1944, page 1959 - 1965, page 1959

Kotler, Philip \& Keller, Kevin, 2007, Manajemen Pemasaran, Jilid 1, Edisi 12, Jakarta : PT. Indeks.

Kotler, Philip \& Keller, Kevin, 2007, Manajemen Pemasaran, Jilid 2, Edisi 12, Jakarta : PT. Indeks.

Muharromi, Silty, 2015, Analisis Segmentasi, Target dan Posisi Pasar Alat Magnetic Resonance Imaging (MRI) di Rumah Sakit Islam Jakarta Cempaka Putih Tahun 2015, Jakarta

Perhimpunan Nefrologi Indonesia, 2003, Konsensus Dialisis, Jakarta : PERNEFRI(Perhimpunan Nefrologi Indonesia)

Perhimpunan Nefrologi Indonesia, 2011, Konsensus Peritoneal Dialisis Pada Penyakit Ginjal Kronik, Jakarta : PERNEFRI (Perhimpunan Nefrologi Indonesia)

Perhimpunan Nefrologi Indonesia, 2013, Konsensus Transplantasi Ginjal, Jakarta : PERNEFRI (Perhimpunan Nefrologi Indonesia)

Rangkuti, Freddy, 2013, Riset Pemasaran, Jakarta : PT. Gramedia

Republik Indonesia, 2008, Pedoman Pelayanan Hemodialisis Di Sarana Pelayanan Kesehatan, Jakarta : Direktorat Bina Pelayanan Medik Spesialistik, Direktorat Jenderal Bina Pelayanan Medik, Departemen Kesehatan Republik Indonesia

Republik Indonesia, 2010, Peraturan Menteri 
Kesehatan Republik Indonesia Nomor 812 Tahun 2010 Tentang Penyelenggaraan Pelayanan Dialisis Pada Fasilitas Pelayanan Kesehatan Tahun 2010, No 812, Sekertariat Negara, Jakarta

Republik Indonesia, 2009, Undang-Undang Republik Indonesia No 36 Tahun 2009 Tentang Kesehatan, Sekretariat Negara, Jakarta

Rina Amelia, 2006, Rancana Strategis Pengembangan / Peningkatan Rumah Sakit Umum Tanjung Pura Langkat Tahun 2007 / 2015, Medan

Roesli, Rully M.A. 2011, Diagnosis \& Pengelolaan Gangguan Ginjal Akut (“Acute Kidney Injury”) Edisi Kedua, Jakarta: Puspa Swara
Rumah Sakit Dokter Sobirin, 2011, Rencana Strategis Bisnis Rumah Sakit dr Sobirin Tahun 2011 - 2015, Lubuk Linggau

Rumah Sakit Umum Pendidikan Fatmawati, 2015, Rencana Strategis Bisnis RSUP Fatmawati 2015 - 2019, Jakarta : RSUP Fatmawati

Simon Steddon, et al (2014), Oxford Handbook of Nephrology and Hypertension, Second edition, China: C\&C Offset Printing Co.Ltd.

Stanley, Melissa, 2010, Peritoneal Dialysis Versus Hemodialysis (Adult)

Sukandar, Enday, 2006, Gagal Ginjal dan Panduan Terapi Dialisis, Bandung, Bagian Ilmu Penyakit Dalam 